CLINICAL STUDY

\title{
Influence of spironolactone treatment on endothelial function in non-obese women with polycystic ovary syndrome
}

\author{
Katica Bajuk Studen ${ }^{1}$, Miran Šebeštjen ${ }^{2}$, Marija Pfeifer ${ }^{1}$ and Janez Preželj ${ }^{1}$ \\ ${ }^{1}$ Division of Endocrinology, Department of Endocrinology, Diabetes and Metabolic Diseases and ${ }^{2}$ Department of Cardiology, University Medical Center, \\ Zaloska 7, 1000 Ljubljana, Slovenia
}

(Correspondence should be addressed to K Bajuk Studen; Email: katica.bajuk@gmail.com)

\begin{abstract}
Objective: Accumulating evidence connects polycystic ovary syndrome (PCOS) with increased risk of cardiovascular disease. Endothelial dysfunction is present in PCOS and represents an early, reversible marker of cardiovascular damage. As androgens and renin-angiotensin-aldosterone system are implicated in the atherogenesis process of PCOS, we tested the hypothesis that treatment with spironolactone, an androgen and mineralocorticoid receptor blocking drug, might reverse endothelial dysfunction in PCOS.

Patients: A total of 30 non-obese PCOS patients, compared with 20 body mass index matched control subjects, were evaluated. PCOS patients were given spironolactone $100 \mathrm{mg}$ daily in 21-day long intervals followed by a 7-day pause, for 6 months.

Measurements: Flow-mediated dilatation (FMD), glyceryl trinitrate-induced dilatation, free testosterone, androstenedione, DHEA-sulfate, total, low-density lipoprotein (LDL)-, high-density lipoproteincholesterol, and triglycerides were determined at baseline and after 6 months.

Results: Results are expressed as median (25-75th percentile). At baseline, FMD was significantly lower in PCOS patients than in controls: $6.0(0.0-11.7)$ vs $10.2(6.8-15.9) \%, P=0.018$. This difference disappeared after 6 months of spironolactone treatment, as FMD in PCOS patients significantly increased to $8.3(5.7-10.3) \%, P=0.034$, and was no longer different from controls. In PCOS patients, serum androgen levels did not change during treatment, while total and LDL-cholesterol decreased significantly from $4.8(4.1-5.1) \mathrm{mmol} / \mathrm{l}$ to $4.4(3.9-4.8) \mathrm{mmol} / \mathrm{l}$ and from $2.5(2.1-3.1)$ to 2.2. (2.1-2.5) $\mathrm{mmol} / \mathrm{l}, P<0.05$ and $P<0.05$ respectively.

Conclusion: Treatment with spironolactone normalized endothelial function and improved cholesterol levels in non-obese PCOS patients.
\end{abstract}

European Journal of Endocrinology 164 389-395

\section{Introduction}

Polycystic ovary syndrome (PCOS) is a common endocrine disorder affecting women of reproductive age. PCOS is associated with multiple cardiovascular risk factors, including hypertension, obesity, insulin resistance, and type 2 diabetes (1). A higher frequency of subclinical atherosclerosis in PCOS women has been observed in many studies (2-4). There are also accumulating data linking PCOS with cardiovascular disease (CVD), although a large prospective trial is still missing $(5,6)$.

Endothelial dysfunction is an early, preclinical, and potentially reversible sign of cardiovascular pathology $(7,8)$. It has been observed in PCOS patients in several studies (9-11). Endothelial dysfunction in PCOS is linked to significant abnormalities in androgen levels, lipoprotein profile, blood pressure, and insulin resistance (12). In addition, components of renin-angiotensin-aldosterone system that can induce endothelial dysfunction have been found to be increased in PCOS (13).

Spironolactone is used as an antiandrogenic drug in patients with PCOS, especially if hirsutism or other clinical signs of androgen excess is the problem (14). Spironolactone has antiandrogenic and antimineralocorticoid properties (15). This dual action makes it an appropriate candidate drug for ameliorating endothelial dysfunction in patients with PCOS. Based on this presumption, the study was designed to test the influence of spironolactone treatment on endothelial function in non-obese PCOS patients.

\section{Subjects and methods}

In this study, 30 women presenting with PCOS in our outpatient clinic were enrolled along with 20 healthy women with regular menstrual cycles and no clinical 
androgenism or biochemical hyperandrogenemia to serve as control subjects.

The diagnosis of PCOS was based on National Institutes of Health (NIH) criteria (16). Clinical hyperandrogenism was defined as the presence of hirsutism, represented by a modified Ferriman-Gallwey score of 7 or more, persistence of acne during the third decade of life or later, or the presence of androgenetic alopecia. Hyperandrogenemia was diagnosed if the level of any of the three androgens determined - free testosterone, androstenedione and/or DHEA-sulfate (DHEA-S) - was above the 95th percentile of normal female population values. Menstrual dysfunction was defined by more than six cycles with length of more than 35 days (oligomenorrhea), or when a patient had not had any menstrual bleeding for three consecutive months during the previous year. Body mass index (BMI) was calculated as individual's body weight divided by the square of her height. The homeostasis model assessment insulin resistance index (HOMA-IR) was calculated as: (fasting glucose $(\mathrm{mmol} / \mathrm{l}) \times$ fasting insulin $(\mathrm{mU} / \mathrm{l}) / 22.5)(17,18)$.

Women taking antiandrogens or oral contraceptives within 6 months prior to the study entry and with BMI of 30 or more, hyperprolactinemia, thyroid disease, hypertension, diabetes mellitus, and other chronic diseases were all excluded from the study. Possible Cushing's syndrome or non-classic congenital adrenal hyperplasia was ruled out if needed. All heavy smokers were excluded as well. Current smokers were requested not to smoke $12 \mathrm{~h}$ before the hemodynamic study. There was a comparable number of smokers in both groups (three controls and six PCOS).

The study conformed to the principles outlined in the Declaration of Helsinki and was approved by the national ethical committee. All subjects gave their written informed consent before entering the study.

Patients and controls were assessed with a detailed medical history and examination. To make biochemical and hormonal determinations, blood samples were obtained from all subjects before hemodynamic studies after overnight fasting. Patients were prescribed spironolactone $100 \mathrm{mg}$ daily and advised to start taking it on the fifth day of menstrual cycle (or on any day if amenorrhea) and to take it in 21-day intervals followed by a 7-day pause regardless of bleeding for 6 months (until the next evaluation), as routinely used in clinical practice (19). No side effects were reported during the study. Both groups were advised to follow their usual eating and exercise routine. After 6 months, all subjects of the study were reevaluated with a clinical history and examination, followed by biochemical and hormonal assessment and the hemodynamic study.

\section{Assays}

Glucose, total cholesterol, low-density lipoprotein (LDL) cholesterol, high-density lipoprotein (HDL) cholesterol, and triglycerides were measured with a standard photometric method (reagents: Roche Diagnostics, biochemical analyzer: Hitachi Modular, Roche Diagnostics). LH, FSH, plasma aldosterone, and insulin were measured by a chemiluminescent immunometric assay (Siemens Medical Solutions Diagnostics, Deerfield, IL, USA). Androstenedione and DHEA-S were determined by a specific double antibody RIA using ${ }^{123}$ I-labeled hormones (Diagnostic Systems Laboratories, Webster, TX, USA). Free testosterone was determined by a coated tube RIA (Diagnostic Products Corporation, Los Angeles, CA, USA). Plasma renin activity was measured by radioimmunological competition assay using RIA kit (Immunotech A Beckmann Coulter Company, Brea, CA, USA). Intra-assay variations ranged from 1.6 to $6.3 \%$, and inter-assay variations ranged from 5.8 to $10.5 \%$ for the applied methods.

\section{Hemodynamic studies}

Endothelium-dependent flow-mediated dilatation (FMD) and endothelium-independent glyceryl trinitrate (GTN)induced dilatation of the brachial artery were studied using a high resolution B mode Advanced Technology Laboratories 5000 ultrasound system with a $7 \mathrm{MHz}$ linear array transducer, according to the method established by Celermajer and described in detail previously $(20,21)$. FMD was expressed as the percentage change of the diameter after reactive hyperemia relative to the baseline diameter. A period of $10 \mathrm{~min}$ was allowed for vessel recovery, after which a further resting scan was taken. GTN-induced dilatation was provoked by sublingual administration of $400 \mu \mathrm{g}$ of GTN, which acts as a nitric oxide (NO) donor. The final scan was performed 4.5 min later. Endothelium-independent dilatation was expressed as the percentage change in the diameter after GTN administration relative to the baseline scan. All measurements were carried out by the same investigator, blinded regarding patient/control status. To assess the reproducibility of measurements, 38 subjects were selected at random for repeated vascular studies. The correlation coefficient between the absolute differences and mean values of paired measurements was $0.92, P<0.05$.

\section{Statistical analysis}

Since the primary goal of the study was to investigate changes in FMD before and after therapy, we calculated that 30 patients would provide $80 \%$ power at the $5 \%$ level to detect an absolute increase of $2.5 \%$, the least significant change of the method in our operators' hand. The normality of data was assessed using the Kolmogorov-Smirnov test. As the majority of variables were non-normally distributed, the data are expressed as median (25-75th percentile). In variables with distributions significantly skewed, a logarithmic transformation was applied to produce approximately normal distribution before performing further analysis. 
Table 1 Baseline characteristics of women with polycystic ovary syndrome (PCOS) and controls.

\begin{tabular}{|c|c|c|c|}
\hline & $\begin{array}{l}\text { Controls }(n=20) \\
\text { Median (25-75th percentile) }\end{array}$ & $\begin{array}{c}\text { PCOS group }(n=30) \\
\text { Median (25-75th percentile) }\end{array}$ & $P$ value \\
\hline Age (years) & $25(23.0-28.5)$ & $23.5(21.0-26.0)$ & $<0.01$ \\
\hline $\mathrm{BMI}\left(\mathrm{kg} / \mathrm{m}^{2}\right)$ & $22(19.9-23.3)$ & $23.1(20.5-24.9)$ & 0.06 \\
\hline Systolic BP (mmHg) & $105.0(97.5-110.0)$ & $110.0(105.0-115.0)$ & 0.26 \\
\hline Diastolic BP (mmHg) & $67.5(60.0-75.0)$ & $70.0(70.0-80.0)$ & 0.06 \\
\hline Waist circumference (cm) & $73.0(69.5-78.0)$ & $82.0(74.5-88.0)$ & $<0.01$ \\
\hline Fasting glucose $(\mathrm{mmol} / \mathrm{l})$ & $5.1(4.9-5.5)$ & $5.3(5.0-5.6)$ & 0.55 \\
\hline Fasting insulin (mIU/l) & $5.0(3.6-8.0)$ & $7.2(4.6-9.1)$ & 0.35 \\
\hline HOMA-IR & $1.2(0.7-1.9)$ & $1.8(1.0-2.2)$ & 0.39 \\
\hline LH (IU/I) & $5.2(3.6-8.6)$ & $9.4(6.5-12.5)$ & $<0.02$ \\
\hline FSH (IÚ/I) & $6.1(3.7-6.7)$ & $5.5(4.6-6.4)$ & 0.82 \\
\hline DHEA-S $(\mu \mathrm{mol} / \mathrm{l})$ & $4.5(4.1-5.7)$ & $8.2(5.9-10.2)$ & $<0.01$ \\
\hline Androstenedione (nmol/l) & $5.8(4.8-7.2)$ & $11.5(9.9-14.4)$ & $<0.01$ \\
\hline Free testosterone $(\mathrm{pmol} / \mathrm{l})$ & $2.8(1.7-5.0)$ & $8.0(5.0-10.4)$ & $<0.01$ \\
\hline Total cholesterol $(\mathrm{mmol} / \mathrm{l})$ & $4.3(3.6-4.6)$ & $4.8(4.1-5.1)$ & 0.1 \\
\hline HDL-cholesterol (mmol/l) & $1.9(1.6-2.2)$ & $1.7(1.5-2.0)$ & 0.67 \\
\hline LDL-cholesterol (mmol/l) & $2.4(1.4-2.5)$ & $2.5(2.1-3.1)$ & $<0.05$ \\
\hline Triglyceride $(\mathrm{mmol} / \mathrm{l})$ & $0.8(0.7-0.9)$ & $0.9(0.7-1.2)$ & 0.21 \\
\hline ApoB $(g / l)$ & $0.7(0.6-0.8)$ & $0.9(0.7-0.9)$ & $<0.03$ \\
\hline Serum potassium (mmol/l) & $4.13(3.95-4.52)$ & $4.21(3.95-4.42)$ & 0.42 \\
\hline Plasma aldosterone (nmol/l) & $0.33(0.23-0.48)$ & $0.25(0.17-0.52)$ & 0.77 \\
\hline Plasma renin activity ( $\mu \mathrm{g} / \mathrm{l}$ per hour) & $0.5(0.27-0.89)$ & $0.56(0.3-0.76)$ & 0.63 \\
\hline
\end{tabular}

Unpaired two-sample $t$-test was used for comparison between patients and controls at baseline and between the two groups after 6 months. Paired $t$-test was used for comparing data at baseline and after 6 months within each group. To assess the univariate relationship between the changes in variables and the FMD change with therapy, Pearson's correlation coefficients were computed. $P$ values of $<0.05$ were considered significant. Data analysis was performed using Statistica, version 7.1 (StatSoft, Inc., 2005, Tulsa, OK, USA).

\section{Results}

Baseline characteristics of women with PCOS and controls are shown in Table 1. Women with PCOS had lower age, bigger waist circumference, and higher LH, DHEA-S, androstenedione, free testosterone, LDLcholesterol and apolipoprotein B (apoB) levels, but they did not differ significantly in BMI, blood pressure, fasting glucose, fasting insulin, HOMA-IR, FSH, total cholesterol, HDL-cholesterol, triglyceride, serum potassium, plasma aldosterone, and plasma renin activity levels. A HOMA-IR value $>2$ was observed in three controls and nine PCOS patients. Plasma aldosterone was significantly higher in this subgroup of PCOS patients than in the subgroup with HOMA-IR $<2$ $(n=21), 0.44(0.24-0.59)$ vs $0.23(0.14-0.38) \mathrm{nmol} / \mathrm{l}$, $P=0.05$.

At baseline, FMD was significantly lower in PCOS patients than in controls, $6.0(0.0-11.7)$ vs 10.2 (6.8-15.9) \%, $P=0.018$. GTN-induced dilatation was also lower in PCOS patients than in the control group, $21.3(14.8-27.2)$ vs $26.5(20.0-31.4) \%, P=0.03$ (Table 2). After 6 months of spironolactone therapy, there was a statistically significant increase in FMD in the PCOS group, while FMD in the control group was unchanged. There was no significant difference in FMD between the PCOS and the control groups after 6 months, 8.3 (5.7-10.3) vs 9.4 (7.1-15.3) \% (Fig. 1).

Plasma levels of androgens (DHEA-S, androstenedione, and free testosterone), which were significantly increased in PCOS patients, did not change significantly during therapy (Table 3).

BMI and waist circumference did not change during 6 months of therapy, $23.6(21.2-25.6)$ vs 23.3

Table 2 Brachial artery FMD and GTN-induced dilatation at baseline and after 6 months in control and PCOS groups. PCOS group was treated with spironolactone for 6 months. Data are expressed as median (25-75th percentile).

\begin{tabular}{lccl}
\hline Characteristics & Baseline & After 6 months & $P$ value \\
\hline PCOS group & & & \\
FMD (\% of change) & $6.0(0.0-11.7)$ & $8.3(5.7-10.3)$ & 0.034 \\
GTN (\% of change) & $21.3(14.8-27.2)$ & $23.3(15.6-27.6)$ & 0.62 \\
Control group & $10.2(6.8-15.9)$ & $9.4(7.1-15.3)$ & 0.94 \\
FMD (\% of change) & $26.5(20.0-31.4)$ & $22.2(18.9-28.6)$ & 0.13 \\
GTN (\% of change) & &
\end{tabular}




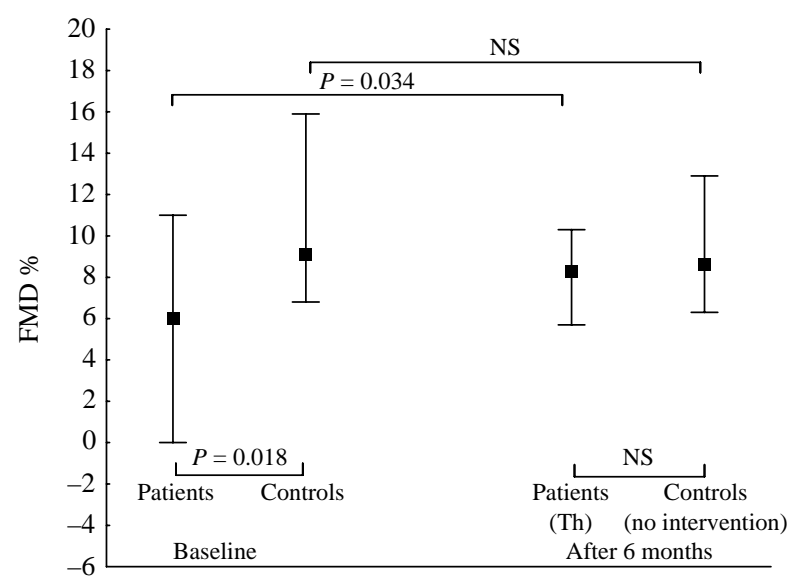

Figure $1 \mathrm{FMD} \%$ (median + interquartile range) in PCOS patients and control group at baseline and after 6 months; PCOS patients treated with spironolactone. NS, non significant.

$(20.7-25.1) \mathrm{kg} / \mathrm{m}^{2}$ and $82.0(74.5-88.0)$ vs 80.5 $(73.0-88.0) \mathrm{cm}(P=0.88$ and 0.77 respectively).

Serum total and LDL-cholesterol decreased, but there were no changes in HDL-cholesterol, triglycerides, and apoB with spironolactone treatment (Table 3).

FMD change in PCOS patients after 6 months of therapy with spironolactone was found to correlate with basal total cholesterol $(\beta=-0.51 ; P=0.042)$ and LDLcholesterol $(\beta=-0.49 ; P=0.011)$, while the association with apoB levels was borderline $(\beta=-0.40$; $P=0.071)$. There were no significant correlations with basal serum androgen levels or with HOMA-IR.

When assessing correlations between FMD change and changes in laboratory parameters, no significant correlations were found.

\section{Discussion}

In this study, we showed that 6 months of spironolactone treatment reversed endothelial dysfunction in non-obese PCOS patients. To our knowledge, this is the first study to investigate the effect of spironolactone, a drug routinely used in PCOS treatment, on endothelial function in PCOS.

Healthy endothelium plays a pivotal role in multiple mechanisms essential for the maintenance of the vascular homeostasis, mostly through the activities of nitric oxide. Endothelial dysfunction is the initial step in the process of atherogenesis (8). Brachial artery FMD is a reliable marker of endothelial function and has been reported as a predictor of incident cardiovascular events in adult population (22). It is a cheap, repeatable, and non-invasive measure of endothelial function and provides a unique opportunity for early assessment of possible treatment benefit, complementing endpoints of structural arterial disease and cardiovascular outcomes that take much longer and are more expensive to study (23). We found endothelial dysfunction in young nonobese PCOS patients, which is in concordance with previously published data (12). This suggests that even non-obese PCOS patients have an increased risk for CVD and may gain particular benefit from treatment that improves endothelial function.

The improvement in endothelial function with spironolactone treatment in our study might be due to its antiandrogenic effects. Endothelial dysfunction in PCOS patients was found to be associated among other factors also to androgens $(10,11,13,24)$. Androgen receptors are present on the vessel wall (25), and testosterone was shown to worsen endothelial function in experimental atherosclerosis (26), suggesting that androgens might operate as proatherogenic factors in PCOS. As expected, there was no significant change in serum androgen levels during spironolactone treatment in our study as spironolactone exerts its antiandrogenic effects primarily through competitive binding to androgen receptor, although it is also a weak inhibitor of testosterone biosynthesis (27). Our findings are in accordance with the report by Spritzer et al. (27), who evaluated spironolactone as an effective drug for hirsutism in PCOS patients. An inhibition of steroidogenesis by spironolactone therapy occurring through an effect on the cytochrome $\mathrm{P} 450$ system has been observed, but a decrease in the

Table 3 Serum androgens, lipids, HOMA-IR, potassium, plasma aldosterone, and renin activity in polycystic ovary syndrome patients before and after 6 months of therapy with spironolactone, expressed as median (25-75th percentile).

\begin{tabular}{lcrr}
\hline Parameter & Baseline & After therapy & $P$ value \\
\hline DHEA-S $(\mu \mathrm{mol} / \mathrm{l})$ & $8.2(5.9-10.2)$ & $7.8(6.0-8.4)$ & 0.51 \\
Androstenedione $(\mathrm{nmol} / \mathrm{l})$ & $11.5(9.9-14.4)$ & $10.7(8.4-14.2)$ & 0.33 \\
Free testosterone $(\mathrm{pmol} / \mathrm{l})$ & $5.9(4.6-9.9)$ & 0.18 \\
Total cholesterol $(\mathrm{mmol} / \mathrm{l})$ & $4.8(4.0-1-4) .1)$ & $4.4(3.9-4.8)$ & $<0.02$ \\
$\mathrm{HDL}-$ cholesterol $(\mathrm{mmol} / \mathrm{l})$ & $1.7(1.5-2.0)$ & $1.8(1.5-2.0)$ & 0.42 \\
LDL-cholesterol $(\mathrm{mmol} / \mathrm{l})$ & $2.5(2.1-3.1)$ & $2.2(2.1-2.5)$ & $<0.04$ \\
Triglyceride $(\mathrm{mmol} / \mathrm{l})$ & $0.9(0.7-1.2)$ & $0.8(0.7-1.1)$ & 0.11 \\
ApoB $(\mathrm{g} / \mathrm{l})$ & $0.9(0.7-0.9)$ & $0.8(0.7-1.0)$ & 0.06 \\
$\mathrm{HOMA}-\mathrm{IR}$ & $1.8(1.0-2.2)$ & $1.62(1.21-2.31)$ & 0.52 \\
Serum potassium $(\mathrm{mmol} / \mathrm{l})$ & $4.21(3.95-4.42)$ & $4.08(3.94-4.21)$ & 0.45 \\
Plasma aldosterone $(\mathrm{nmol} / \mathrm{l})$ & $0.25(0.17-0.52)$ & $0.64(0.42-1.22)$ & $<0.01$ \\
Plasma renin activity $(\mu \mathrm{g} / \mathrm{l} \mathrm{per} \mathrm{hour)}$ & $0.56(0.3-0.76)$ & $1.01(0.64-1.75)$ & $<0.01$ \\
\hline
\end{tabular}


activity of the cytochrome was reported only at very high doses or under in vitro experimental conditions, for example in bovine and human adrenal cortical mitochondria $(28,29)$.

Spironolactone-induced improvement of endothelial function could also be in part a consequence of aldosterone antagonism, as shown in studies investigating chronic heart failure (30). PCOS patients were reported to have significantly increased aldosterone levels in comparison with controls, although values were still within the normal range (13). Hyperreninemia was also reported in PCOS patients (31). We found higher aldosterone levels in the subgroup of PCOS patients with a HOMA-IR value above 2 , which is in accordance with a previous report (13). Aldosterone impairs endothelial function through increased NADPH oxidase activity and mitochondrial generation of reactive oxygen species, which decrease bioavailability of nitric oxide $(15,32)$. The RALES study showed that spironolactone $(25 \mathrm{mg})$, added to conventional therapy for chronic heart failure, dramatically reduced mortality (30). Yet, spironolactone in the study did not have a clinically significant hemodynamic effect. A subsequent study designed to investigate possible underlying mechanisms showed that in this group of patients, spironolactone improved endothelial function, increased nitric oxide bioactivity, and inhibited vascular AngI/AngII conversion (32). However, spironolactone ( $50 \mathrm{mg} /$ day) impaired endothelial function in patients with type 2 diabetes without heart failure, possibly due to the worsening of glycemic control and increase in plasma angiotensin II that were observed with spironolactone treatment (33). As many PCOS patients have impaired glucose tolerance or type 2 diabetes, they probably represent a subgroup where the beneficial effect of spironolactone treatment on endothelial function might be less likely, and further research is needed in different subgroups of PCOS patients.

Regarding the lipid profile, the PCOS group in our study had significantly higher levels of LDL-cholesterol and apoB than the control group, although still within the normal range, as demonstrated in previous studies in PCOS patients $(34,35)$. There was no significant difference in HDL-cholesterol and triglyceride levels as our patients were non-obese. This is in accordance with studies of lipid metabolism in PCOS patients stratified into obese and non-obese groups $(34,36)$. Atherogenic lipids, particularly LDL-cholesterol, are responsible for a wide range of cellular dysfunctions within the vessel wall. The effects on endothelial cells disrupt normal control of vasomotion, through a reduction in effective nitric oxide activity, development of procoagulant surface, chronic low-grade inflammation, and abnormal cell growth. There is growing evidence that these changes in cellular function respond rapidly to changes in atherogenic lipids (37). Although our PCOS patients were not overtly dyslipidemic, our findings support the notion that hyperandrogenism might contribute to an adverse lipoprotein profile independently of obesity (36). After treatment with spironolactone, levels of total and LDL-cholesterol significantly decreased in spite of unchanged lifestyle routine, including diet, and no change in body weight. Changes in the lipid profile may be a direct consequence of inhibition of androgen action, since improved lipoprotein profile has been reported in PCOS patients with androgen blockade using the drug flutamide (38).

Nitrate-mediated vasodilatation was also impaired in PCOS patients compared with control women, in agreement with previous studies (12). The vasodilatory response to GTN is considered to be a function of both vascular smooth muscle relaxation (direct action of GTN on the vascular smooth muscle) and the endothelial response to hyperemia caused by GTNinduced dilatation of the resistance vessels. Loss of this hyperemic flow component of the GTN response may explain the impairment observed in the PCOS group; however, a smooth muscle abnormality in the conduit arteries of these women cannot be excluded. Increased stiffness in the carotid and brachial arteries in PCOS patients in comparison with control women has been previously reported $(39,40)$.

The limitations of our study include relatively small number of subjects, which may have limited the power of this study to fully explore associations between the metabolic and hormonal variables and FMD. The numbers, however, are comparable with other published studies. In our study, which addresses the early cardiovascular pathology in young PCOS patients, the diagnosis of PCOS was based on NIH criteria. Since there is still no final consent about the uniform criteria for PCOS, we chose the NIH criteria because they better define the population of PCOS patients that are at higher risk for cardiometabolic complications (41). However, NIH criteria exclude milder forms of PCOS with regular menses or without clinical/biochemical signs of hyperandrogenism. Finally, there is a slight, although statistically significant trend towards older age in the control subjects; so the demonstration of the difference in FMD between patients and controls has even greater weight, as advancing age is associated with reduction of arterial elasticity and vascular function (42).

In conclusion, our study showed that spironolactone improves endothelial function in non-obese PCOS patients. However, further research should encompass a more diverse spectrum of PCOS patients.

\section{Declaration of interest}

The authors declare that there is no conflict of interest that could be perceived as prejudicing the impartiality of the research reported.

\section{Funding}

This work was supported by Slovenian Research Agency (contract number 1000-05-310112). 


\section{References}

1 Ehrmann DA. Polycystic ovary syndrome. New England Journal of Medicine 2005352 1223-1226. (doi:10.1056/NEJMra041536)

2 Meyer C, McGrath BP \& Teede HJ. Overweight women with polycystic ovary syndrome have evidence of subclinical cardivascular disease. Journal of Clinical Endocrinology and Metabolism 200590 5711-5716. (doi:10.1210/jc.2005-0011)

3 Carmina E, Orio F, Palomba S, Longo RA, Cascella T, Colao A, Lombardi G, Rini GB \& Lobo RA. Endothelial dysfunction in PCOS: role of obesity and adipose hormones. American Journal of Medicine 2006119 e1-e6. (doi:10.1016/j.amjmed.2005.10.059)

4 Vryonidou A, Papatheodorou A, Tavridou A, Terzi T, Loi V, Vatalas I-A, Batakis N, Phenekos C \& Dionyssiou-Asteriou A. Association of hyperandrogenemic and metabolic phenotype with carotid intima-media thickness in young women with polycystic ovary syndrome. Journal of Clinical Endocrinology and Metabolism 200590 2740-2746. (doi:10.1210/jc.2004-2363)

5 Shaw LJ, Bairey Merz N, Azziz R, Stanczyk FZ, Sopko G, Braunstein GD, Kelsey SF, Kip KE, Cooper-Dehoff RM, Johnson BD, Vaccarino V, Reis SE, Bittner V, Hodgson TK, Rogers W \& Pepine CJ. Postmenopausal women with a history of irregular menses and elevated androgen measurements at high risk for worsening cardiovascular event-free survival: results from the National Institutes of Health - National Heart, Lung and Blood Institute Sponsored Women's Ischemia Syndrome Evaluation. Journal of Clinical Endocrinology and Metabolism 200893 1276-1284. (doi:10.1210/jc.2007-0425)

6 Christian RC, Dumesic DA, Behrenbeck T, Oberg AI, Sheedy PF II \& Fitzpatrick LA. Prevalence and predictors of coronary artery calcification in women with polycystic ovary syndrome. Journal of Clinical Endocrinology and Metabolism $2003 \mathbf{8 8} 2562-2568$. (doi:10.1210/jc.2003-030334)

7 Wierzbicki AS, Chowienczyk PJ, Cockroft JR, Brett SE, Watts GF, Jenkins BS \& Ritter JM. Cardiovascular risk factors and endothelial dysfunction. Clinical Science 2004107 609-615. (doi:10.1042/ CS20040078)

8 Deanfield JE, Halcoy JP \& Rabelink TJ. Endothelial function and dysfunction. Circulation 2007115 1285-1295. (doi:10.1161/ CIRCULATIONAHA.106.652859)

9 Paradisi G, Steinberg HO, Hempfling A, Cronin J, Hook G \& Shepard MK. Polycystic ovary syndrome is associated with endothelial dysfunction. Circulation 2001103 1410-1415.

10 Orio F Jr, Palomba S, Cascella T, DeSimone B, DiBiase S \& Russo T. Early impairment of endothelial structure and function in young normal-weight women with polycystic ovary syndrome. Journal of Clinical Endocrinology and Metabolism $2004894588-4593$. (doi:10.1210/jc.2003-031867)

11 Diamanti-Kandarakis E, Alexandraki K, Protogerou A, Piperi C, Papamichael C, Aessopos A, Lekakis J \& Mavrikakis M. Metformin administration improves endothelial function in women with polycystic ovary syndrome. European Journal of Endocrinology 2005 152 749-756. (doi:10.1530/eje.1.01910)

12 Kravariti M, Naka KK, Kalantaridou SN, Kazakos N, Katsouras CS, Makrigiannakis A, Paraskevaidis EA, Chrousos GP, Tsatsoulis A \& Michalis LK. Predictors of endothelial dysfunction in young women with PCOS. Journal of Clinical Endocrinology and Metabolism 200590 5088-5095. (doi:10.1210/jc.2005-0151)

13 Cascella T, Palomba S, Tauchmanovà L, Manguso F, DiBiase S, Labella D, Giallauria F, Vigorito C, Colao A, Lombardi G \& Orio F. Serum aldosterone concentration and cardiovascular risk in women with polycystic ovary syndrome. Journal of Clinical Endocrinology and Metabolism 200691 4395-4400. (doi:10. 1210/jc.2006-0399)

14 Brown J, Farquhar C, Lee O, Toomath R \& Jepson RG. Spironolactone versus placebo or in combination with steroids for hirsutism and/or acne. Cochrane Database of Systematic Reviews 200915 CD000194. (doi:10.1002/ 14651858.CDO00194.pub2)
15 Sowers JR, Whaley-Connell A \& Epstein M. Narrative review: the emerging clinical implications of the role of aldosterone in the metabolic syndrome and resistant hypertension. Annals of Internal Medicine $2009150776-783$.

16 Zawadski JK \& Dunaif A. Diagnostic criteria for polycystic ovary syndrome: towards a rational approach. In Polycystic Ovary Syndrome, pp 377-384. Eds A Dunaif, JR Givens, FP Haseltine \& GR Merriam. Boston, MA: Blackwell Scientific, 1992.

17 Matthews DR, Hosker JP, Rudenski AS, Naylor BA, Treacher DF \& Turner RC. Homeostasis model assessment: insulin resistance and $\beta$-cell function from fasting plasma glucose and insulin concentrations in man. Diabetologia 198528 412-419. (doi:10.1007/ BF00280883)

18 Baillargeon JP, Jakubowicz DJ, Iuorno MJ, Jakubowicz S \& Nestler JE. Effects of metformin and rosiglitazone, alone and in combination, in nonobese women with polycystic ovary syndrome and normal indices of insulin sensitivity. Fertility and Sterility 2004 82 893-902. (doi:10.1016/j.fertnstert.2004.02.127)

19 Shapiro G \& Evron S. A novel use of spironolactone: treatment of hirsutism. Journal of Clinical Endocrinology and Metabolism 1980 51 429-432. (doi:10.1210/jcem-51-3-429)

20 Celermajer DS, Sorensen KE, Gooch VM, Spiegelhalter DJ, Miller OI, Sullivan ID, Lloyd JK \& Deanfield JE. Non-invasive detection of endothelial dysfunction in children and adults at risk of atherosclerosis. Lancet $19923 \mathbf{3 4 0} 1111-1115$. (doi:10.1016/ 0140-6736(92)93147-F)

21 Jensterle M, Sebestjen M, Janez A, Prezelj J, Kocjan T, Keber I \& Pfeifer M. Improvement of endothelial function with metformin and rosiglitazone treatment in women with polycystic ovary syndrome. European Journal of Endocrinology 2008 159 399-406. (doi:10.1530/EJE-08-0507)

22 Yeboah J, Folsom AR, Burke GL, Johnson C, Polak JF, Post W, Lima JA, Crouse JR \& Herrington DM. Predictive value of brachial flow-mediated dilatation for incident cardiovascular events in a population-based study: the multi-ethnic study of atherosclerosis. Circulation $2009 \mathbf{1 2 0} 502-509$. (doi:10.1161/CIRCULATIONAHA.109.864801)

23 Charakida M, Masi S, Luscher T, Kastelein JJP \& Deanfield JE. Assessment of atherosclerosis: the role of flow-mediated dilatation. European Heart Journal 201031 2854-2861. (doi:10.1093/ eurheartj/ehq340)

24 Romualdi D, Costantini B, Selvaggi L, Giuliani M, Cristello F, Macri F, Bompiani A, Lanzone A \& Guido M. Metformin improves endothelial function in normoinsulinemic PCOS patients: a new perspective. Human Reproduction 200823 2127-2133. (doi:10. 1093/humrep/den230)

25 Fujimoto R, Morimoto I, Morita E, Sugimoto H, Ito Y \& Eto S. Androgen receptors, 5 $\alpha$-reductase activity and androgendependent proliferation of vascular smooth muscle cells. Journal of Steroid Biochemistry and Molecular Biology $1994 \mathbf{5 0}$ 169-174. (doi:10.1016/0960-0760(94)90025-6)

26 Hutchison SJ, Sudhir K, Chou TM, Sievers RE, Zhu BQ, Sun YP, Deedwania PC, Glantz SA, Parmley WW \& Chatterjee K. Testosterone worsens endothelial dysfunction associated with hypercholesterolemia and environmental tobacco smoke exposure in male rabbit aorta. Journal of the American College of Cardiology 199729 800-807. (doi:10.1016/S0735-1097(96)00570-0)

27 Spritzer PM, Lisboa KO, Mattiello S \& Lhullier F. Spironolactone as a single agent for long-term therapy of hirsute patients. Clinical Endocrinology $2000 \mathbf{5 2}$ 587-594. (doi:10.1046/j.1365-2265. 2000.00982.x)

28 Menard RH, Stripp B \& Gillette JR. Spironolactone and testicular cytochrome p-450: decreased testosterone formation in several species and changes in hepatic drug metabolism. Endocrinology 197494 1628-1636. (doi:10.1210/endo-94-6-1628)

29 Chiau-Cheng S, Suzuki K, Sadee W \& Harding BW. Effect of spironolactone, canrenone and K-canreonate on cytochrome p-450 and $11 \beta$ - and 18 hydroxilation in bovine and human adrenal cortical mitochondria. Endocrinology $1976 \quad 99$ 1097-1102. (doi:10.1210/endo-99-4-1097) 
30 Diamanti-Kandarakis E, Economou FN, Livadas E, Tantalaki E, Piperi C, Papavassiliou AG \& Panidis D. Hypereninemia characterizing women with polycystic ovary syndrome improves after metformin therapy. Kidney \& Blood Pressure Research 200932 24-31. (doi:10.1159/000201791)

31 Pitt B, Zannad F, Remme WJ, Cody R, Castaigne A, Perez A, Palensky J \& Wittes J. The effect of spironolactone on morbidity and mortality in patients with severe heart failure. New England Journal of Medicine $1999341 \quad 709-717 . \quad$ (doi:10.1056/ NEJM199909023411001)

32 Farquharson CA \& Struthers AD. Spironolactone increases nitric oxide bioavailability, improves endothelial vasodilator dysfunction, and supresses vascular angiotensin I/angiotensin II conversion in patients with chronic heart failure. Circulation $2000 \mathbf{1 0 1}$ 594-597.

33 Davies JI, Band M, Morris A \& Struthers AD. Spironolactone impairs endothelial function and heart rate variability in patients with type 2 diabetes. Diabetologia 200447 1687-1694. (doi:10. 1007/s00125-004-1510-8)

34 Valkenburg O, Steegers-Theunissen RP, Smedts HP, DallingaThie GM, Fauser BC, Westerveld EH \& Laven JS. A more atherogenic serum lipoprotein profile is present in women with polycystic ovary syndrome: a case-control study. Journal of Clinica Endocrinology and Metabolism 200893 470-476. (doi:10.1210/ jc.2007-1756)

35 Demirel F, Bideci A, Cinaz P, Camurdan MO, Biberoglu G, Yesilkaya E \& Hasanoglu A. Serum leptin, oxidized low density lipoprotein, and plasma asymmetric dimethylarginine levels and their relationship with dyslipidemia in adolescent girls with polycystic ovary syndrome. Clinical Endocrinology $2007 \mathbf{6 7}$ 129-134. (doi:10.1111/j.1365-2265. 2007.02849.x)
36 Legro RS, Kunselman AR \& Dunaif A. Prevalence and predictors of dyslipidemia in women with polycystic ovary syndrome. American Journal of Medicine 2001111 607-613. (doi:10.1016/SO0029343(01)00948-2)

37 Adams MR, Kinlay S, Blake GJ, Orford JL, Ganz P \& Selwyn A. Atherogenic lipids and endothelial dysfunction: mechanisms in the genesis of ischemic syndromes. Annual Review of Medicine 200051 149-167. (doi:10.1146/annurev.med.51.1.149)

38 Diamanti-Kandarakis E, Mitrakou A, Raptis S, Tolis G \& Duleba AJ. The effect of a pure antiandrogen receptor blocker, flutamide, on the lipid profile in the polycystic ovary syndrome. Journal of Clinical Endocrinology and Metabolism $1998 \mathbf{8 3}$ 2699-2705. (doi:10. 1210/jc.83.8.2699)

39 Lakhani K, Seifalian AM \& Hardiman P. Impaired carotid viscoelastic properties in women with polycystic ovaries. Circulation 2002106 81-85. (doi:10.1161/01.CIR.0000020681.19400.8A)

40 Kelly CJG, Speirs A, Gould GW, Petrie JR, Lyall H \& Connell JMC. Altered vascular function in young women with polycystic ovary syndrome. Journal of Clinical Endocrinology and Metabolism 2002 87 742-746. (doi:10.1210/jc.87.2.742)

41 Azziz R. Controversy in clinical endocrinology - diagnosis of polycystic ovary syndrome: the Rotterdam Criteria are premature. Journal of Clinical Endocrinology and Metabolism $2006 \mathbf{9 1}$ 781-785. (doi:10.1210/jc.2005-2153)

42 Herrera MD, Mingorance C, Rodriguez-Rodriguez R \& Alvarez de Sotomayor M. Endothelial dysfunction and aging: an update. Ageing Research Reviews 20109 142-152. (doi:10.1016/j.arr. 2009.07.002)

Received 24 November 2010

Accepted 13 December 2010 